\title{
Nurse's Health Education In Families Of Pediatric Surgical Clients
}

\author{
Elsa Naviati ${ }^{1}$, Sari Sudarmiati ${ }^{2}$
}

${ }^{1,2}$ Jurusan Keperawatan, Fakultas Kedokteran, Universitas Diponegoro

\section{Article Info}

Article History:
Accepted April 13
Key words:
Health education
Nurses
Pediatric surgical

\section{PENDAHULUAN}

Optimalisasi peran perawat dapat menurunkan efek hospitalisasi jangka pendek maupun jangka panjang pada anak dan orang tua. Potter dan Perry (2005) memaparkan bahwa salah satu peran dari perawat adalah sebagai educator dimana perawat mendemonstrasikan prosedur, memberikan informasi penting dan mengevaluasi hasil pembelajaran.

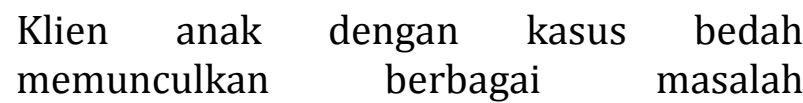
keperawatan dari fisik hingga psikologis yang dirasakan tidak hanya anak namun juga keluarga. Adapun masalah yang dirasakan klien dan keluarga yang paling sering dikeluhkan adalah nyeri, gangguan konsep diri, ketidakseimbangan nutrisi dan cairan Browne, Flanigan, \& Mc Comeiskey (2008).

Harmonisasi interaksi antara perawat, klien dan keluarga (orangtua) memberikan pengaruh besar terhadap perawatan anak di rumah sakit. Interaksi terbangun dari hubungan yang baik antara perawat, anak dan orangtua. Penelitian oleh Espezel dan Canam (2003) membahas interaksi perawat, anak dan orangtua. Dalam penelitian tersebut menjelaskan bahwa hubungan baik antara orangtua dan perawat akan mempermudah proses perawatan anak. Orangtua merasa nyaman dengan perawat yang merawat dan mampu memahami anak dengan baik. Membangun hubungan antara perawat dan orangtua termasuk didalamnya adalah membangun komunikasi dan berbagi informasi dalam

Corresponding author:

Elsa Naviati

elsanaviatizainal@gmail.com

Media Keperawatan Indonesia, Vol 1 No 2, Juni 2018

e-ISSN: 2615-1669

DOI:10.26714/mki.1.2.2018.1-5 
hal ini pendidikan kesehatan dari perawat kepada klien dan keluarga.

\section{METODE}

Jenis penelitian yang digunakan adalah penelitian kualitatif. Penelitian ini menggunakan pendekatan fenomenologi yang menggunakan pendekatan deskriptif yang berfokus pada pemahaman tentang respon/keberadaan manusia. Teknik sampling yang digunakan peneliti agar memperoleh sampel yang benar-benar sesuai dengan keseluruhan subjek

HASIL penelitian yaitu purposive sampling. Pengambilan sampel pada penelitian ini berdasarkan titik saturasi. Adapun jumlah partisipan pada penelitian ini adalah 5 perawat. Penelitian ini dilakukan di Ruang Anak RSUP Dr Kariadi Semarang. Alat pengumpul data pada penelitian ini adalah telepon genggam sebagai alat perekam, buku catatan dan alat tulis serta panduan wawancara. Uji keabsahan data dilakukan dengan menggunakan uji kredibilitas, transferabilitas, dependabilitas dan konfirmabilitas.

\section{Proses Reduksi Dari Kata Kunci Menjadi Tema}

\begin{tabular}{|c|c|c|c|c|}
\hline No & Tema & Sub Tema & Kategori & Kata Kunci \\
\hline \multirow[t]{5}{*}{1} & \multirow[t]{5}{*}{$\begin{array}{l}\text { Pendidikan } \\
\text { Kesehatan } \\
\text { sebelum operasi }\end{array}$} & \multirow[t]{2}{*}{$\begin{array}{l}\text { Persiapan } \\
\text { operasi }\end{array}$} & Puasa & $\begin{array}{l}\text { Pasien kan harus puasa } 6 \text { jam sebelum operasi } \\
\text { Ga boleh makan minum sekitar } 6 \text { jam sebelum } \\
\text { operasi } \\
\text { Dilarang makan minum sebelum operasi, berapa yaa, } \\
6 \text { jam rata-rata } \\
\text { Stop makan minum beberapa jam sebelum operasi }\end{array}$ \\
\hline & & & Kecemasan & $\begin{array}{l}\text { Ibu kadang sulit diajak komunikasi mendekati jam } \\
\text { operasi } \\
\text { Sudah diberi edukasi lupa lagi karena ingat operasi } \\
\text { Gimana ya mbak, operasinya kayak apa } \\
\text { Boleh minum ga anak saya, nangis kejer }\end{array}$ \\
\hline & & \multirow[t]{3}{*}{ Intra operasi } & $\begin{array}{l}\text { Tim } \\
\text { kesehatan }\end{array}$ & $\begin{array}{l}\text { Dikenalkan nama dokter yang mau ngoperasi } \\
\text { Dikasi tau siapa aja yang nanti melakukan operasi } \\
\text { dan perawatnya juga }\end{array}$ \\
\hline & & & Prosedur & $\begin{array}{l}\text { Diberi tahu seperti apa nanti waktu operasi, sadar } \\
\text { atau ga } \\
\text { Lama operasi kita sampaikan juga bagaimana } \\
\text { rangkaian jalannya operasi } \\
\text { Diinformasikan dulu sebelum operasi, bahwa anak } \\
\text { akan dilakukan prosedur apa saat nanti di meja } \\
\text { operasi }\end{array}$ \\
\hline & & & Pemulihan & $\begin{array}{l}\text { Kapan pasien mulai sadar } \\
\text { Kapan pulang dari kamar operasi } \\
\text { Diinfokan bagaimana nanti waktu pertama datang di } \\
\text { ruang anak } \\
\text { Apa saja yang perlu diperhatikan setelah operasi saat } \\
\text { nanti di ruangan }\end{array}$ \\
\hline \multirow[t]{3}{*}{2} & \multirow[t]{3}{*}{$\begin{array}{l}\text { Pendidikan } \\
\text { kesehatan } \\
\text { setelah operasi }\end{array}$} & $\begin{array}{l}\text { Pencegahan } \\
\text { infeksi }\end{array}$ & $\begin{array}{l}\text { Mencuci } \\
\text { tangan }\end{array}$ & $\begin{array}{l}\text { Setiap habis operasi, pasti diajari terus mencuci } \\
\text { tangan } \\
\text { Diberitahu cara mencucui tangan yang benar } \\
\text { Ditanya sudah bisa cuci tangan belum, kalau belum } \\
\text { diajati karena beberapa pasien sudah kesekian kali } \\
\text { operasi }\end{array}$ \\
\hline & & \multirow[t]{2}{*}{$\begin{array}{l}\text { Kebutuhan } \\
\text { istirahat }\end{array}$} & $\begin{array}{l}\text { Tirah } \\
\text { baring }\end{array}$ & $\begin{array}{l}\text { Diajarin ibunya agar anaknya di tempat tidur dulu ga } \\
\text { boleh turun turun } \\
\text { Suruh diam anteng bobo aja di tempat tidur }\end{array}$ \\
\hline & & & $\begin{array}{l}\text { Istirahat } \\
\text { tidur }\end{array}$ & $\begin{array}{l}\text { Dianjurkan agar anak tidur lebih lama } \\
\text { Sebisa mungkin anak tidur optimal }\end{array}$ \\
\hline
\end{tabular}




\begin{tabular}{|c|c|c|c|c|}
\hline No & Tema & Sub Tema & Kategori & Kata Kunci \\
\hline & & & & $\begin{array}{l}\text { Diberi tahu agar anak istirahat dengan cara tidur agar } \\
\text { pemulihan lebih baik }\end{array}$ \\
\hline \multirow[t]{3}{*}{3} & \multirow[t]{3}{*}{$\begin{array}{l}\text { Nutrisi setelah } \\
\text { operasi }\end{array}$} & \multirow[t]{3}{*}{ Diet bertahap } & Diet air gula & $\begin{array}{l}\text { Diberi air gula dulu agar tidak kaget } \\
\text { Minum air gula setelah sadar, kasian sudah puasa } \\
\text { lama } \\
\text { Kalau sudah boleh minum, kami beri air gula dulu }\end{array}$ \\
\hline & & & Diet susu & $\begin{array}{l}\text { Buat pasien bayi diet ya ASI kalau tidak ya susu } \\
\text { formula } \\
\text { Pasien bayi langsung minum ASI setelah boleh minum } \\
\text { seperti tercantum dalam saran post operasi dari } \\
\text { anastesi } \\
\text { Kami sediakan susu untuk bayi yang habis operasi } \\
\text { atau kalau ada ASI ya berikan ASI tinggal dilihat } \\
\text { kondisi pasien }\end{array}$ \\
\hline & & & $\begin{array}{l}\text { Makanan } \\
\text { saring dan } \\
\text { lunak }\end{array}$ & $\begin{array}{l}\text { Kalau sudah stabil beri makan saring } \\
\text { Bertahap yaa... habis cair lalu lunak atau saring }\end{array}$ \\
\hline \multirow[t]{2}{*}{4} & \multirow[t]{2}{*}{$\begin{array}{l}\text { Perawatan luka } \\
\text { operasi }\end{array}$} & \multirow[t]{2}{*}{ Ganti balut } & Balut Steril & $\begin{array}{l}\text { Ganti balut kami lakukan setiap hari tapi hanya ganti } \\
\text { pertama yang steril } \\
\text { Tiap hari donk.. steril pasti.. } \\
\text { Harus steril apalagi ganti pertamanya }\end{array}$ \\
\hline & & & Balut bersih & $\begin{array}{l}\text { Perawatan luka dilakukan dengan prinsip bersih } \\
\text { Ganti balut bersih setiap hari }\end{array}$ \\
\hline \multirow[t]{3}{*}{5} & \multirow[t]{3}{*}{$\begin{array}{l}\text { Mengatasi myeri } \\
\text { setelah operasi }\end{array}$} & \multirow[t]{2}{*}{ Tanpa obat } & $\begin{array}{l}\text { Napas } \\
\text { dalam }\end{array}$ & $\begin{array}{l}\text { Diajari kok bu. Kami ajari tarik napas dalam } \\
\text { Disuruh napas dalam kalau nyeri } \\
\text { Ibunya dan anaknya kami ajari semua, napas dalam. }\end{array}$ \\
\hline & & & Distraksi & $\begin{array}{l}\text { Kan anak suka maen game ya kita bebaskan biar ga } \\
\text { rewel. } \\
\text { Diajak ke ruang bermain } \\
\text { Diajak cerita } \\
\text { Ibunya putar musik di sebelah pasien biar bisa bobo }\end{array}$ \\
\hline & & Dengan obat & Analgetik & $\begin{array}{l}\text { Sesuai protap kami beri asam mefenamat } \\
\text { Pasti kami beri analgetik, kan sakit } \\
\text { Berkala kami beri pereda nyeri, asmet atau sanmol } \\
\text { tergantung order }\end{array}$ \\
\hline
\end{tabular}

\section{PEMBAHASAN}

\section{Pendidikan kesehatan sebelum operasi}

Pendidikan kesehatan sebelum operasi didefinisikan sebagai tindakan suportif yang dilakukan perawat untuk membantu klien dan keluarganya dalam mengurangi tingkat kecemasan klien dan menghadapi stress yang dihadapi selama perioperatif (Lemone dan Burke, 2004). Alasan kecemasan yang terjadi pada keluarga diantaranya adalah nyeri setelah pembedahan, perubahan bentuk fisik dan kegagalan operasi (Potter dan Perry, 2005). Keluarga mengharapkan dukungan dari perawat terkait aspek pengambilan keputusan, tambahan pengetahuan, keterampilan dan perubahan perilaku. Hasil penelitian Kilicarslan, Kurnaz dan Kecialan pada tahun 2012 menyebutkan bahwa informasi terstruktur yang diberikan mampu menurunkan tingkat kecemasan orangtua dengan anak yang akan dilakukan operasi. Demikian pula penelitian Kurniawan, Armiyati dan Astuti pada tahun 2013 menjelaskan adanya pengaruh yang signifikan dari pendidikan kesehatan terhadap tingkat kecemasan.

\section{Pendidikan kesehatan setelah operasi}

Berdasarkan hasil penelitian yang dilakukan, pendidikan kesehatan setelah operasi yang dilakukan perawat diutamakan untuk pencegahan infeksi. Adapun salah satunya adalah pendidikan kesehatan tentang mencuci tangan. 
Penelitian Haverstick, et.al (2017) menjelaskan bahwa mencuci tangan dapat menurunkan angka infeksi di Rumah Sakit. Mencuci tangan dapat dilakukan dengan menggunkaan air dan sabun atau antiseptik cair yang ada di tempat tidur klien. Hal ini dilakukan sebelum makan, setelah makan dan setelah buang air. Selain itu, perawat selalu mengingatkan klien untuk meningkatkan kualitas istirahat tidurnya. Istirahat dan tidur adekuat membantu proses penyembuhan (Bergner, 2014).

\section{Nutrisi setelah operasi}

Salah satu kebutuhan penting klien yang harus diperhatikan oleh perawat yaitu kebutuhan nutrisi. Perawat harus mengkaji status nutrisi pre operasi klien. Penelitian oleh Durakbasa, et.al pada tahun 2014 menjelaskan bahwa mengidentifikasi status nutrisi sangat diperlukan oleh klien anak dengan kasus bedah. Meskipun hanya minoritas, ternyata masih didapatkan anak post operasi yang menderita malnutrisi. Padahal, nutrisi sangat penting untuk perbaikan jaringan pos operasi dan penyembuhan luka. Kekurangan nutrisi pre operasi dapat mengakibatkan penyembuhan luka yang tidak optimal.

\section{Perawatan luka operasi}

Luka operasi yang dipertahankan lembab adalah lebih baik. Laju epitelisasi luka yang ditutup polyetylen dua kali lebih cepat daripada luka yang dibiarkan kering. Migrasi epidermal pada luka superficial lebih cepat pada suasana lembab daripada kering. Perawatan luka lembab tidak meningkatkan infeksi. Lingkungan lembab meningkatkan migrasi sel epitel ke pusat luka dan melapisinya sehingga luka lebih cepat sembuh (Smeltzer dan Bare, 2002).

Penggantian balutan dilakukan sesuai kebutuhan tidak hanya berdasarkan kebiasaan, melainkan disesuaikan terlebih dahulu dengan tipe dan jenis luka.
Penggunaan antiseptik hanya untuk yang memerlukan saja karena efek toksinnya terhadap sel sehat. Untuk membersihkan luka hanya memakai normal saline. Citotoxic agent seperti povidine iodine, asam asetat, seharusnya tidak secara sering digunakan untuk membersihkan luka karena dapat menghambat penyembuhan dan mencegah reepitelisasi. Luka dengan sedikit debris dipermukaannya dapat dibersihkan dengan kassa yang dibasahi dengan sodium klorida dan tidak terlalu banyak manipulasi gerakan (Browne, Flanigan, \& Mc Comeiskey (2008).

\section{Mengatasi nyeri setelah operasi}

Setiap klien yang dilakukan pembedahan pasti akan merasakan nyeri. Demikian pula dengan klien anak. Bedanya, klien anak belum dapat mengungkapkan bagaimana nyeri yang mereka rasakan. Perawat harus memantau nyeri klien yang dilakukan operasi secara berkala. Pengkajian nyeri dilakukan rutin seperti halnya memeriksa tanda-tanda vital. Dalam keperawatan holistik, nyeri merupakan salah satu sinyal bahwa terjadi suatu proses pertahanan diri di dalam tubuh Dossey, Keegan \& Guzzetta (2005). Sebelum tindakan pembedahan, klien dan keluarga diberikan penjelasan mengenai nyeri yang mungkin muncul dan penatalaksanaan nyeri baik dari keperawatan yaitu penatalaksanaan tanpa obat maupun medis yaitu dengan menggunakan obat. Manajemen nyeri non farmakologi yang paling sering dilakukan perawat adalah distraksi dan relaksasi. Penelitian oleh Ommen, Kathuria \& Mathur pada tahun 2014 menjelaskan bahwa teknik distraksi efektif menurunkan nyeri. Selain itu juga dilakukan kontrol kognitif atau strategi kognitif. Hal tersebut bermanfaat untuk menghilangkan ketegangan, ansietas yang berlebihan dan relaksasi. Distraksi dilakukan dengan memberikan mainan, atau kegiatan yang mampu mengalihkan klien dari rasa sakit. Selain bermain dapat pula dilakukan dengan mendengarkan musik. Penelitian oleh Cardoso, et.al pada tahun 2017 menyebutkan bahwa terapi 
musik mampu merilekskan fisik anak setelah operasi. Musik membuat anak menjadi lebih tenang dan kooperatif.

\section{REFERENSI}

Bergner, T. (2014). Promoting rest using quiet time innovation in adult neuroscience step down unit. Canadian Journal of Neuroscience Nursing Volume 36, Issue 3, 2014.

Browne, N.T., Flanigan, L.M., \& McComeiskey C.A. (2008). Pocket guide to pediatric surgical nursing. Canada: Jones and Barlett.

Cardoso, e.al. (2017). With words i cannot say: giving new meaning to care through music in cardio pediatric postoperative. Rev Rene. 2017 SeptOct; 18(5):655-62.

Dossey, B.M., Keegan, L., \& Guzzetta, C.E. (2005). Holistic nursing : a handbook for practice 4th edition. United State of America: Jones and Bartlett Publisher.

Durakbasa, et.al. (2014). The prevalence of malnutrition and effetiveness of strongkids tool $\mathrm{i}$ the identification of malnutrition risk among pediatric surgical patients. Balkan Med J 2014;31:313-21.

Espezel, H. \& Canam, C. (2003) Parent-nurse interactions: care of hospitalized children. Journal of Advanced Nursing, 44, 34-41.

Haverstick, S., et.al. (2017). Patients hand washing and reducing hospital acquired infection. CriticalCareNurse Vol 37, No. 3, June 2017.

Kilicarslan, E., Kurnaz, F. \& Kecialan, R. (2012). Effect of planned information provision on anxiety of parent of children who underwent cardiac surgery. Hemşirelikte Araştırma Geliștirme Dergisi 2012-1.

Kurniawan, A., Armiyati, Y. \& Astuti, R. (2013). Pengaruh pendidikan kesehatan pre operasi terhadap tingkat kecemasan pada pasien pre operasi hernia di RSUD Kudus. Jurnal Keperawatan Fikkes vol. 6 No. 2 Oktober 2013.

Lemone, P. \& Burke, K. (2004). Medical surgical nursing critical thinking in client care. Third edition. New Jersey: Pearson Education.

Ommen, S., Kathuria, O.K., \& Mathur, R.G. (2014). Behavioral distress during invasive pediatric procedure among school age children. International Journal of Nursing Education. July-December 2014, Vol. 6, No.2.

Potter, P.A; \& Perry, A.G. (2005). Buku Ajar Fundamental Keperawatan. Jakarta: EGC.

Smeltzer, S.C; \& Bare, B.G. (2002). Buku Ajar Keperawatan Medikal Bedah. Jakarta: EGC. 